\title{
Analysis of the Present Situation with Insufficient Intrinsic Motivation to Higher Education(HD)in Xinjiang,China
}

\author{
Lixia Zhu * \\ College of Life Science, \\ Tarim University, \\ Xinjiang, Alar, China \\ e-mail: judyzhu1@sina.com
}

\begin{abstract}
In Xinjiang, there are few reports on the theory of HD from local colleges and universities; there are no environment and atmosphere for teachers to think and research on HD. The development of education has the obvious lack of intrinsic motivation. The reason is that the individual of teacher lacks the deep understanding of the essence of the specialty education and expresses occupation burnout; it is hard to introduce the teachers with high accomplishments in HD; talent drain becomes serious in local universities; teachers team is unstable, and so on. Xinjiang university has obvious dependence and convergence to the universities out of Xinjiang without independent exploration spirit; the national unified plan and unified management make the educative information from educational bottom hard to deliver to the educative top resulting in the passivity of education and weakness or loss of educational ability of local universities in Xinjiang.
\end{abstract}

\section{Keywords- Higher Education; present situation; Xinjiang}

\section{INTRODUCTION}

With the rapid development of the national economy, Xinjiang has experienced the momentum of rapid economic growth, which increases the demand for senior talents. The State and local governments have provided the support of funds and policy for the construction and development of the universities, and huge funds are continuously investigated to the construction of local universities. The average appropriation of each student is above the average of the western provinces [1].

Starting from 2001 the East-west University Partnership Plan, through 10 years' implementation, has founded the partnership between 41 eastern universities and 12 universities in Xinjiang. The five project, "College-department Partnership", "Construction of Discipline Platform", "Creation of Academic Team", "Fostering of Network Learning", "Quality Education of Students", have comprehensively constructed and continuously improved the sustainable "Blood-creation Model" of Partnership, resulting in the fast development of HD of Xinjiang[2-3].

\section{THE QUICK DEVELOPMENT OF UNIVERSITY IN XINJIANG IMPLIES THE RISK OF HD DEVELOPMENT STRAYING FROM THE RIGHT PATH OF EDUCATION ACTIVITIES.}

Dewey thinks education offers a wealth of resources for science, because of the complexity of educational activities, a variety of discipline should be taught with a series of education activities, only education should be took as the core among education activities, the problems related education could be solved. The essences of teaching behavior without education as core is a kind of abscondence and surrender with efficiency and comfort or a moment just seeking answers from some of the material with so-called science dignity [4].Based on Duwey's theory, the present situation of education in Xinjiang shows the quick development of in the major colleges and universities implies the possibility of the departure from the essence of HD with the risk of university development straying from the right path of education activities.

In Xinjiang, the scale of undergraduate colleges and universities has increased, meanwhile vocational schools has increased around the province, while the number of the schoolage students shows a decreasing trend. So, colleges and universities have been fighting to enroll students as many as possible. For a good survival, colleges and universities put too much emphasis on employment and their scientific research level to display their educational level. Although the efforts are worked, the effect is low because of the special region located in the western China, the mixed minority, the tough environment and complexity, and the lagged economic and educational development in Xinjiang. The local HD in Xinjiang is much more complex and much more important beyond our thoughts. The colleges and universities are not only the incubator of talents to meet the demand of local economic development, but also have the special contribution to the society stability. The graduates from these local colleges and university should be fully educated not only in professional knowledge but also armed with sound ideological attitudes to work in Xinjiang forever. The later needs more attention from educators and teachers full of educational knowledge. Ignore these basic characteristics of the local college and universities in Xinjiang will lead to a series of serious problems in education. 
For example, with the rapid development of colleges and universities, the employment rate of graduates from Tarim University has broken continuing growth, and even has obviously declined trend removed since 2003[4].In addition to the external factors such as without a sound employment mechanism, the internal factors is insufficient education to the students, this results in the situation of "Jobs not lack, but graduates not choose" that there are a few of free employments in companies and in grass-roots unites of government, although few graduates choose them as their ideal jobs[5]. Majority of graduates directly give up the grass-roots posts, and even most of minority students choose to go home after their graduation. Comparing to the students with the traits of "bottom go to, stay, do good" graduated in early developments of Tarim University, the current graduates lack of the "Nanniwan" spirit to work hard in harsh environment of Xinjiang. With the background of massive education, the professional skills learned during the four or three years and employment guidance taught within a few hours on graduations can't solve the series of educational problems such as "Jobs not lack, but graduates not choose". To solve the problems related to the local HD in xinjiang, some important fact should be considered including the importance of stabilities of Xinjiang to the whole nation and the complexity of humanities environment in the region, meanwhile, the educational system to guide graduates with different and long-term suitable measures according to different personalities and different conditions should also be carefully constructed with hard work.

As far as Xinjiang HD is concerned, it is not a sound behavior just copying the habitual methods or measures in the universities out of Xinjiang provinces without fully aware of Xinjiang actual situation of HD. For example, it mainly considers the scientific research work to certificate the teaching level of a teacher instead of the educative activities between students and teachers. It is hard to say the science research work of teachers could influence graduates with positive effect. Maybe the number of less than $10 \%$ the students with expectation of employment to do science research in Tarim university [5]could show not a good idea to certificate teacher's educative level by their science research work in Xinjiang universities. Without considering the actual situation of lagged both science research work and HD, blindly following the universities and colleges out of Xinjiang to do science research work with ignoring the educative behavior will pull faculties' attention and financial support away from teaching students, resulting in weaker and weaker educational ability for local universities with sacrifice of improving students educated level.

In addition to the copying others universities, introducing talents into the colleges and universities in Xinjiang(CUX)focus on high diploma because the higher diploma seems to mean higher science research ability. The fact is that the professional and educational development of these teachers introduced is insufficient, with the serious lack of a deep understanding how to develop educative ability [6]. In 2020, there is a plan in Autonomous Region of Xinjiang to introduce talents in to local universities with the conditions that undergraduates with master degree taking up more than $80 \%$, with doctorate degrees more than $50 \%$ [7]. For a person, the master or doctorate degrees can only represent past knowledge and science research work, but can't reflect the actual educating or educated ability facing the complex and lag education environment of Xinjiang. Besides, the talents introduced from all corners of the country, don't know much about the local culture, customs, habits, a mixed ethnic minorities in Xinjiang. The more and the faster these talents are introduced, the more of them are not to be able to quickly integrate into the local culture, not mention to don't achieve the mutual recognition with local culture and the degree of mutual fusion. This group of teachers with such background is difficult to effectively perform their educative activities on Xinjiang native students, particularly on minority students. It is obvious the less teaching effective, the less teachers fully and smoothly communicate with students with full knowledge on their students, especially their cultural background. Thus, there is a big mistake between faculties in Xinjiang universities, namely, it is the weak studying ability of local students that contribute to their poor academic achievement and even their low job rate, local students seems much slower-witted than students enrolled from other places out of Xinjing with so-called quickly thinking brain. It seems that local students are the problem. Is it true? The answer is absolutely not. The fundamental reason is that teachers' teaching behavior does not accord with local students' learning behavior reflecting the local ecological culture born and bred them. That is to say, it is the failure of educative activities without integration of education behavior of teachers into local ecological culture resulting in weak the effect of education, and even in negatively develop local HD. The high degree of diploma would cause the degradation instead of promotion of HD if the educational quality of talents and the actual situation of HD in Xinjiang were ignored completely.

\section{THE RESEARCH ON HD THEORY OF XINJIANG COLLEGES AND UNIVERSITIES IS SERIOUSLY INSUFFICIENT.}

Although some scholars believe that HD research in China is up to mature period, research on HD in Chinese western colleges and universities is yet less and more lagged [8]. The number of reports on Xinjiang HD published in the key educational journals is just total of 79, only accounting for less than $0.1 \%$ of 78187 articles from 1980 to 2013 year (table 1). Among the limited number of articles, 36 papers are from Shihezi University, 14 Xinjiang University, 13 Xinjiang Normal University, 11 other local Universities including vocational schools. The contents of these articles almost involve the economy, politics and law etc. However, HD research reported in these papers is almost zero. Among the 79 papers, only 2 funded by the National Plan of Educational Sciences, 1 Doctor Subject Foundation of the Ministry of Education of China and 1 by the National Social Science Fund.

The "11th 5 years" and "12 th 5 years" projects on education from the Ministry of Education are the representative of the highest research on education in China, and they are distributed with the widest range into most of Chinese colleges and universities. In past 7 years, 11 projects were approved in the CUX, including 4 ones relate to HD, which accounted for 2574 items $0.27 \%$ and $0.15 \%$, respectively (table 2 ). The Studied subjects almost all involve in social science instead of 
education. These numbers prove that the research on HD theory of Xinjiang colleges and universities is seriously insufficient, not mention to get such achievement with high quality in the aspect of HD. Some historic reason is related to poor educational development in Xinjiang, the most important things are the lack of introspection and self- motivation to develop HD in the whole community of CUX, which leads educative activities into much more troubles in local colleges and universities.

TABLE I. ARTICLES PUBLISHED FROM XINJIANG COLLEGES AND UNIVERSITIES

\begin{tabular}{|c|c|c|c|c|c|c|c|}
\hline Periodical & $\mathrm{a}$ & $\mathrm{b}$ & $\mathrm{c}$ & $\mathrm{d}$ & $\mathrm{e}$ & $\mathrm{f}$ & $\mathrm{h}$ \\
\hline Research on Higher Engineering Education & 0 & 0 & 0 & 0 & 0 & 0 & 0 \\
\hline The study of HD & 1 & 3 & 1 & 0 & 0 & 0 & 2 \\
\hline Theoretical front of HD & 2 & 0 & 1 & 0 & 0 & 0 & 1 \\
\hline HD exploration & 1 & 0 & 0 & 0 & 0 & 1 & 0 \\
\hline Heilongjiang HD research & 2 & 12 & 2 & 3 & 0 & 0 & 3 \\
\hline The HD in Jiangsu & 1 & 3 & 0 & 0 & 0 & 0 & 0 \\
\hline Chinese HD & 3 & 2 & 0 & 1 & 3 & 0 & 1 \\
\hline The academic degree and graduate education & 0 & 0 & 0 & 0 & 0 & 0 & 1 \\
\hline Modern university education & 0 & 3 & 0 & 1 & 0 & 0 & 0 \\
\hline Chinese HD research & 1 & 0 & 1 & 0 & 0 & 0 & 0 \\
\hline China University Teaching & 2 & 2 & 0 & 0 & 0 & 0 & 4 \\
\hline Education Research of Tsinghua university & 0 & 0 & 0 & 0 & 0 & 0 & 0 \\
\hline Study on the development of Education & 0 & 4 & 0 & 0 & 0 & 0 & 0 \\
\hline Peking University Education Review & 0 & 0 & 0 & 0 & 0 & 0 & 0 \\
\hline Teacher education research & 0 & 0 & 0 & 0 & 0 & 0 & 0 \\
\hline Fudan Education & 0 & 0 & 0 & 0 & 0 & 0 & 0 \\
\hline Modern Education Science & 0 & 3 & 0 & 0 & 0 & 0 & 0 \\
\hline The modern education management & 0 & 0 & 0 & 0 & 0 & 0 & 0 \\
\hline Total & 14 & 36 & 5 & 5 & 3 & 1 & 13 \\
\hline
\end{tabular}

Note: a. Xinjiang University; b. Shihezi University; c.Tarim University; d.

Xinjiang Agricultural University; e. Xinjiang University Of Finance and Economics; f. Kashi Normal schoo; h. Xinjiang Normal school; i. Yili Normal

school

\section{THE LACK OF INTROSPECTION AND SELF- MOTIVATION TO DEVELOP HD IN XINJIANG}

Teachers of CUX ignore the important role of educational theory in their educational profession, yet do not really perform professional responsibilities in educative activities. Teachers with authorized teaching certification don't mean that they have such ability to perform their educative skills so well to deal with the lagged educational situation in Xinjiang. Most of teachers take themselves as tools to teach their professional knowledge to students, meanwhile they are busy with science research work which is thought a good way to improve their teaching skills, besides their income and social states. For these teachers, there are no time, no energy and no the concept to improve their educational profession with strong introspection and active-self motivation. In addition to these, the teachers working in Xinjiang colleges and universities are too young in average age and too exotic to local humanities culture in Xinjiang to help them improve their educational abilities with enough educational knowledge and experience.

Indeed, the intrinsic motivation to improve the HD in xinjiang is due to the lack of talents and instability of teacher team. Talent shortage is a result of the backward of the remote region in economy and the whole education field. There is much more difficult to introduce talents with high educated quality into Xinjiang colleges and university, there is yet not such probability to cultivate teachers with high professional quality in HD in Xinjiang, there is local senior talents such as doctors with $\mathrm{PhD}$ to take the teaching jobs in small scale and with poor quality. There is also serious talents drain of experienced teachers in Xinjaing because of low pay, tough working environment as mentioned before [10], leading to teacher team in colleges and universities unsteady, it is obviously proven that over 70 percentages of the teachers working Tarim University have the wills to leave away Tarim University one day [11]. Instability of teacher team directly causes teacher not concentrated on educational work.

TABLE II. THE PROJECTS PRESIDED IN XINJIANG COLLEGES AND UNIVERSITIES

\begin{tabular}{|c|c|c|c|}
\hline year & Project name & $\mathrm{rd}$ & $\mathrm{rt}$ \\
\hline \multirow[t]{2}{*}{2006} & $\begin{array}{l}\text { Study on educational reform of bilingual teachers of } \\
\text { Minority Nationalities }\end{array}$ & & \multirow{2}{*}{$2 / 227$} \\
\hline & $\begin{array}{c}\text { Research on Information Literacy of the teachers in } \\
\text { Xinjiang minority regions }\end{array}$ & & \\
\hline 2007 & $\begin{array}{l}\text { On the application of case teaching methods of } \\
\text { modern distance education "three model" of the rural } \\
\text { primary and middle schools in Minority Areas }\end{array}$ & & $1 / 277$ \\
\hline \multirow[b]{2}{*}{2008} & $\begin{array}{l}\text { Study of ethnic minority education in Xinjiang in } \\
\text { late Qing Period }\end{array}$ & & \multirow{2}{*}{$2 / 341$} \\
\hline & $\begin{array}{l}\text { Study on the culture of Xinjiang minority students in } \\
\text { science experiment teaching and innovative ability }\end{array}$ & & \\
\hline \multirow{6}{*}{2009} & $\begin{array}{c}\text { Intervention strategies fall in agricultural and } \\
\text { pastoral areas of Xinjiang Kirgiz ethnic 13-15 years } \\
\text { old students' physique }\end{array}$ & & \multirow{6}{*}{$6 / 458$} \\
\hline & $\begin{array}{l}\text { Study on improving the community action Uygur } \\
\text { bilingual teachers professional quality }\end{array}$ & & \\
\hline & $\begin{array}{l}\text { Research on the development of bilingual teachers } \\
\text { in primary and middle schools in Xinjiang Uygur } \\
\text { teaching ability }\end{array}$ & & \\
\hline & $\begin{array}{l}\text { Research on the learning model of professional } \\
\text { development for teachers, online case }\end{array}$ & yes & \\
\hline & $\begin{array}{c}\text { And characteristics of project } 211 \text { university } \\
\text { development orientation of new in the Western } \\
\text { Ethnic Areas }\end{array}$ & yes & \\
\hline & $\begin{array}{l}\text { Xinjiang with the class status of mental health of the } \\
\text { disabled students, restricting factors and } \\
\text { psychological support system construction }\end{array}$ & & \\
\hline \multirow{2}{*}{2010} & $\begin{array}{l}\text { Under the background of multi culture in Xinjiang } \\
\text { minority college students language use and cultural } \\
\text { adaptation problems and Countermeasures }\end{array}$ & yes & \multirow{2}{*}{$2 / 452$} \\
\hline & $\begin{array}{c}\text { Study of the minority teachers of physics new } \\
\text { curriculum adaptability of Xinjiang junior high } \\
\text { school }\end{array}$ & & \\
\hline 2011 & $\begin{array}{l}\text { Ideological and political education of the Kazakh } \\
\text { ethnic minority college students in Xinjiang }\end{array}$ & yes & $1 / 400$ \\
\hline 2012 & $\begin{array}{c}\text { The transformation of Xinjiang civic culture and } \\
\text { national identity research }\end{array}$ & & $1 / 419$ \\
\hline
\end{tabular}

$\mathrm{rd}$ : the project is related to the HD or not; rt : the number of projects in Xinjiang / total number

The occupation burnout emotional of faculties in Chinese colleges and universities [12] is also a common phenomenon in Xinjiang colleges and universities. The teacher lost love of enthusiasm for their occupation, specific expression is not satisfied teaching performance with extremely alienation to their occupation. Burnout emotional in colleges and universities is like an infectious disease to infect whole teachers group with. To analyze the occupation burnout emotional, there are some factors worth to be mentioned here. The more 
important thing is that the teachers in Xinjiang universities have no hope to do something as their wills in HD. Young teacher lack the platform to perform themselves in their occupation. In Xinjiang universities, the leader or authorized professors control the teaching resources, while young teachers have not enough educational resources to do some research on local HD. For these leader or authorized professors, they care more their fame and income which derived from their researching projects, while they wound not put much attention to research local education, meanwhile, there is little possibility for a young teachers to get such projects which is too few to be presided by these young faculties mainly because they lack social connections. The huge money from state are invested on the construction of facilities in Xinjiang universities, but not on the educational theory research related to local HD. The senior teachers are too clearer about the resistance to improve the statues of Xinjiang HD and too experienced in old educative activities to be changed themselves. All of these main factors lead the occupation burnout emotional for teachers who are working in Xinjiang universities.

In addition to analyze reasons of the lack of educational motivation to research HD at the teacher's point, some reasons should be attributed to the colleges and universities. Xinjiang colleges and universities blindly follow ones out of Xinjiang, modeling on their education mode and using their education philosophy without local digestion. Xinjiang colleges and universities have the serious lack of independent local educational exploration spirits, the dependent characteristic is obvious, especially much more dependent on the colleges universities which give partner assistance to Xinjiang ones. This dependence is clear to be observed from the macroscopic view and macroscopic control measures on HD to the running universities idea, curriculum design, and other educative details. The theory and methods on HD from other universities are just copied to the HD of Xinjiang, especially in the eager for quick success and quick profit, most colleges and universities are naturally driven to copy these existed and habitual doings without willing to take any effort to study hard on the Xinjiang local HD.

In addition, the HD in our country is influenced by the national unified plan and unified management (NUPM), there is no exception in Xinjiang. Due to development in all aspects lagging behind in Xinjiang, the development of Xinjiang HD much more depends on NUPM without newly reform according local actual situation. The phenomenon is more outstanding in the Xinjiang production and Construction Corps(XPCC). For example, Tarim university partly supported by (XPCC), the top-level design on the development of the whole university is often be controlled by its competent department at a higher level, therefore, there is congenital defects. The position is important but absent of practical functions, the theory is perfect but its performance is unfruitful, [13]. These defects make the teaching task is ordered from top to bottom, and teachers almost mechanically complete them without any further thinking. It is the educational information isn't a delivery from educational bottom to educational top which can really reflect the actual situation to give a sound local HD decision-making that results in the passivity of education and weakness or loss of educational ability of universities.

\section{CONCLUSION}

To sum up, there are few reports on the theory of HD in CUX, there are no environment and atmosphere for faculties to research on HD in local colleges and universities, the development of education has the evident lack of intrinsic motivation. The main and direct reason is related to the individual of teacher, they lack the introspection and selfmotivation to improve their educational profession with the occupation burnout, and so on. Besides it is hard to introduce the teachers with high accomplishments in HD, meanwhile there is the lack of cultivating soil for local teachers, and even talent drain become serious in local universities, teachers team is unstable, and so on. In addition to these, Xinjiang colleges and universities has obvious dependence and convergence to the universities out of Xinjiang without independent exploration spirit; the national unified plan and unified management makes the educative information from educational bottom hard to top the educative top resulting in the passivity of education and weakness or loss of educational ability of universities.

\section{ACKNOWLEDGMENT}

This paper is supported by Tarim University HD research project (TDGJ1336)

\section{REFERENCES}

[1] Chiang ruffle. Xinjiang will invest 1000000000 yuan to develop [N]. Chinese education newspaper, 2006-04-17001

[2] Chiang ruffle. Xinjiang 10 years: Xinjiang HD into the fast lane [N]. Chinese education newspaper, 2010-09-09007

[3] Liang Yong. Research and practice of College assistance mode -building sustainability "blood type" University assistance new mode of [J]. Chinese HD research, 2009,02:61-62

[4] Li Hai. The formation and development of multidisciplinary research and HD theory [J] The study of HD, 2004,06:67-70

[5] Yang Baoren, Jing Wong. The employment situation of the graduates of the Tarim University under the new situation [J]. The border economy and culture, 2010,04:71-73

[6] Meng Fanli. FD system in Japan to promote the professional development of university teachers and Its Enlightenment [J]. HD research, 2007,03:5

[7] Xinjiang last year of education expenditure accounted for $6.2 \%$ of GDP in 41300000000 [J]. Study on the development of Education, 2012,01:68

[8] Chen Tingzhu, Cai Wenbo. To enhance the research level of HD to create a new situation of Subject Construction -- China Institute of HD, HD professional committee conference of 2011 [J]. The study of HD, 2011,11:106-109

[9] Cheng Lianghong. Continuous pendulum and potential balance: two routes and the relationship of teacher development $[\mathrm{J}]$. Education research and development, 2012,24:36-41

[10] Zhang Jianren. Some thoughts on the development of HD in Xinjiang [J] Education research and development, 2006,01:50-54.

[11] Wang Xin, Ma Huilan. Study on loss of Tarim University teachers [J]. Modern enterprise education, 2013,06:188-189.

[12] Zhao Bo, Zhang Zhihua. The university teacher occupation tired and career development countermeasures [J].

[13] The HD in Jiangsu, 2012,01:101-102. Yan Wei Hua. Construction and exploration of the planning mechanism[J]. Research on higher engineering education, 2010,03:118-121 